\title{
TIEMPO DE FRONTERAS, UNA VISIÓN GEOPOLÍTICA DE LA FRONTERA SUR DE MÉXICO. DANIEL VILLAFUERTE SOLÍS. MÉXICO: UNICACH, CESMECA, JUAN PABLOS. 2017
}

José Luis González Miranda

Recibido: 07/12/2017 - Aceptado: 12/01/2018

Entre los estudios sobre migración y frontera sur de México existen temas muy locales o específicos (trabajo doméstico, rutas, género, entre otros), pero pocos, como el de Daniel Villafuerte, dan una visión general de toda la frontera donde las profundidades geopolíticas y económicas se entrecruzan con la actualidad social para ofrecer un análisis coherente entre lo local y lo global. A sus trabajos anteriores -el autor es experto en migración, desarrollo y seguridad en la frontera sur- añade en Tiempo de fronteras dos peculiaridades: en primer lugar, las políticas de Estados Unidos que "fronterizan" esta región no son vistas como ruptura de Trump, sino como continuidad; $y$, en segundo lugar, brinda tres realidades que "desfronterizan": albergues, caravanas de madres en busca de sus migrantes "desaparecidos" y "La Bestia". Dos actores -Estados Unidos y los migrantes- son protagonistas de este "campo de batalla": "por un lado, la fuerza de los migrantes y las organizaciones de apoyo y, por otro lado, la fuerza del Estado, a veces en contubernio con grupos delincuenciales" (Villafuerte 235). La lucha entre "fronterización" y "desfronterización" es por lo tanto la tesis central del libro:

En este contexto, la desfronterización es un hecho social relevante propio de la globalización que elimina fronteras al capital en sus distintas representaciones e impone barreras a la movilidad humana, en especial a la migración irregular. Se puede decir que la desfronterización se produce desde arriba y también desde abajo; es una expresión de la lucha de clases en su versión actual que exige la apertura de fronteras (189).

Al análisis marxista que predomina en sus libros, Villafuerte añade aquí una gama de marcos teóricos que ayudan a entender la compleja realidad estudiada, especialmente Foucault y Mbembe, de modo que junto a la lucha de clases se entretejen otros conceptos como biopolítica y necropolítica. Hay otras fuentes, pero sobre todo hay abundantes noticias de medios locales que ponen carne al esqueleto analítico. 
El primer capítulo -Las dimensiones de la frontera sur- no se refiere solo a las dimensiones geográfico-políticas. En lo demográfico, hay una acelerada urbanización de las ciudades. Palenque, por ejemplo, ha multiplicado por ocho su población desde 1980 hasta el 2010. Por su parte, en la dimensión administrativa hay una frontera-filtro que deja pasar muchas mercancías y pocas personas; además, hay un trato desigual a las personas ricas y a las pobres. Palenque recibe 600000 turistas al año (con visa) protegidos por la policía turística y, al mismo tiempo, llegan miles de migrantes (sin visa) perseguidos por diferentes cuerpos policiales que los extorsionan. Fronterización para unos; desfronterización para otros. Lo anterior recuerda la canción de Quilapayún: “abre la muralla, cierra la muralla”. La dimensión sociocultural dibuja, por el contrario, una frontera-encuentro: a diferencia de la frontera norte hay una cultura común, así como recursos naturales, pobreza y violencia a ambos lados. Hay también una dimensión histórica común anterior a la anexión de Chiapas a México (año 1824) y relaciones transfronterizas que no se detuvieron con el Tratado de Límites (año 1882), cuyo Convenio preliminar se firmó, curiosamente, en Nueva York (61), lo cual indica que la preocupación de Estados Unidos por esta frontera es antigua. Y es que siempre ha habido una dimensión económica (café, hule, madera, ganado), proyectos energéticos en el siglo XX (hidroeléctricas, campos petroleros) y hoy megaproyectos como el gasoducto México-Guatemala-Honduras y el nuevo extractivismo de minería y agrocombustibles.

Por último, una dimensión geopolítica ampliada: “de Colombia a México se extiende una serie de fronteras que tienen la función de separar lo deseable de lo indeseable" (104) ¿Por qué el perfil de esos países es tan semejante y por qué viven condiciones parecidas de violencia generalizada? Responde el expresidente de Guatemala, Otto Pérez Molina, desde la cárcel: “El interés de Estados Unidos es extender su presencia en el área frente a Nicaragua y Venezuela, pero también frente al avance de los chinos y los rusos" (107).

Lo anterior se enlaza con el segundo capítulo: La frontera sur en el marco de la geopolítica de Estados Unidos. ¿Cuáles han sido algunos intereses de Estados Unidos? el posible "contagio" revolucionario desde Centroamérica en los años 80, la Iniciativa Mérida sobre seguridad, el Plan Frontera Sur del año 2014... es decir, imponer la "fronterización". Es interesante el documento del Departamento de Estado que se muestra contrario al CA-4 (141-142), el acuerdo migratorio de Guatemala, Honduras, El Salvador y Nicaragua, porque es ejemplo claro de su oposición a la "desfronterización". Veamos dos eventos recientes: la cumbre en Cozumel de Fuerzas Armadas de Estados Unidos, México y Centroamérica, y la Conferencia de Alto Nivel sobre Seguridad y Economía celebrada en junio en la sede del Comando Sur (Miami). Se habló en ambas reuniones de que Estados Unidos, a través del Comando Sur, va a controlar esta frontera incluso con una base en Petén. Aunque el libro no señala estas dos reuniones, porque ocurrieron cuando estaba para salir, el análisis de Villafuerte hacía pronosticar ese paso, 
al igual que la aprobación, mientras escribimos esto, de la escandalosa Ley de Seguridad Interior que promueve la militarización de México.

Al final del capítulo el Instituto Nacional de Migración es presentado como un actor secundario con su política de contención-detención-deportación, corrupciones, y sucesivos planes ligados a la "biopolítica" de Foucault: controlar los cuerpos para hacer "un ajuste de los fenómenos de población a los procesos económicos" (163).

El autor interrumpe estadísticas y teorías para ofrecernos una narrativa del otro bando de esta batalla en el tercer capítulo "Postales de la desfronterización". Esas "postales" serían lo que Mbembe llama "pequeñas insurrecciones" que quieren rehabilitar el cuerpo. Compartir la comida en un albergue, agarrarse de un hierro del tren, o visitar morgues y hospitales en la caravana de madres, son acciones centradas en el cuerpo para resistir a la "necropolítica fronterizadora", si se me permite crear un neologismo Mbembe-Villafuerte. La vida o la muerte de los migrantes dependen de políticas migratorias y no migratorias como la connivencia política con el crimen organizado que realiza un control fronterizo mejor que el del Estado: "el Estado cede o comparte la regulación del espacio a grupos delincuenciales" (233). El narco-Estado "fronteriza" controlando quién pasa y quién "desaparece", mientras las "postales" expresan valores culturales de hospitalidad (albergues), cuidado (caravanas) y resistencia (La Bestia). Las motivaciones de un albergue para dar comida no son económicas. Las madres que traspasan fronteras buscando a sus "desaparecidos" no buscan dinero. En un análisis marxista clásico esas acciones no serían importantes porque el motor de la historia es la economía. Quienes pasan por los albergues se parecen más al lumpen denostado por Marx que a los proletarios revolucionarios. Sin embargo, la acción de migrar, lejos de ser una acción individualista -"como no puedo cambiar mi país, cambio de país"- es una acción política, una desobediencia civil, como la define José Luis Rocha $^{1}$ al hablar del paso irregular de fronteras.

Por último, el capítulo cuarto, "La frontera sur y el desarrollo”, repasa los planes de desarrollo: Plan Puebla Panamá, Proyecto Mesoamérica y ahora la Alianza para la Prosperidad y las Zonas Económicas Especiales (ZEE) como la de Puerto Chiapas, que no avanza al ritmo anunciado, pues lo único que ha crecido es la exportación de minerales $(262,267)$, especialmente titanio a China. El modelo extractivista sigue ahí. Por eso son pertinentes las preguntas del autor: ¿desarrollo de qué, para quién y según quién?

Hace casi treinta años el capitalismo ondeaba la bandera de la libertad de movimientos frente al muro de Berlín construido por el comunismo que simbolizaba inmovilidad forzada pero también desplazamientos forzados (Gulag). Hoy es el capitalismo el que provoca desplazamientos forzados (por megaproyectos) y en otros la inmovilidad forzada por muros, violencia (muchas personas apenas salen de sus barrios) y leyes (doña Alma, salvadoreña, pasó veinte años sin salir de Comalapa por miedo a la "migra" mexicana antes de que la apoyaran en su regularización en el año 2015). Son otros muros. Al caer el muro de Berlín no disminuyeron las fronteras, 
sino que se multiplicaron. Por eso las "postales" tienen tanto valor: son respuesta a la fronterización que inmoviliza unos cuerpos y desplaza otros. Las "postales" desfronterizan haciendo caminar la historia y la libertad. La dialéctica está entre fronterizar o fraternizar. En ese sentido, el libro de Daniel Villafuerte ayuda a comprenderlo y a situarse. Es, por lo tanto, un libro necesario y de lectura ineludible.

\section{Nota}

1 Rocha, José Luis. Migrantes: ¿víctimas sumisas o en desobediencia civil? Revista Envío, 342, 2010. http://www.envio.org.ni/articulo/4234

José Luis González Miranda, sj. Español. Tiene una Maestría en Moral Social sobre Migraciones en Centro Sèvres (París, Francia). Además, es licenciado en teología (UCA, San Salvador) y en medicina (Universidad de Oviedo, España). Coordinador del Equipo Frontera Sur del Servicio Jesuita a Migrantes en Frontera Comalapa (Chiapas, México).

Correo: jolugomi@jesuits.net

ORCID: 0000-0002-3995-1255 